\title{
Design, construction, and validation of an internally lit air-lift photobioreactor for growing algae
}

\author{
Esteban Hincapie ${ }^{1}$ and Ben J. Stuart ${ }^{2 *}$ \\ Department of Mechanical Engineering, Russ College of Engineering and Technology, Ohio University, Athens, OH, USA \\ ${ }^{2}$ Department of Civil Engineering, Russ College of Engineering and Technology, Ohio University, Athens, OH, USA
}

\author{
Edited by: \\ Umakanta Jena, Desert Research \\ Institute, USA \\ Reviewed by: \\ Alberto Scoma, Ghent University, \\ Belgium \\ Ashish Bhatnagar, Maharshi \\ Dayanand Saraswati University, India \\ K. C. Das, University of Georgia, USA \\ *Correspondence: \\ Ben J. Stuart, 122 Stocker Center, \\ Athens, OH 45701, USA \\ e-mail: stuart@ohio.edu
}

A novel $28 \mathrm{~L}$ photobioreactor for growing algae was developed using fiber optics for internal illumination. The proposed design uses the air-lift principle to enhance the culture circulation and induce light/dark cycles to the microorganisms. Optical fibers were used to distribute photons inside the culture media providing an opportunity to control both light cycle and intensity. The fibers were coupled to an artificial light source; however, the development of this approach aims for the future use of natural light collected through parabolic solar collectors. This idea could also allow the use of opaque materials for photobioreactor construction significantly reducing costs and increasing durability. Internal light levels were determined in dry conditions and were maintained above $80 \mu \mathrm{mol} /\left(\mathrm{s} \cdot \mathrm{m}^{2}\right)$. The hydrodynamic equations of the air-lift phenomena were explored and used to define the geometric characteristics of the unit. The reactor was inoculated with the algae strain Chlorella sp. and sparged with air. The reactor was operated under batch mode and daily monitored for biomass concentration. The specific growth rate constant of the novel device was determined to be $0.011 \mathrm{~h}^{-1}$. The proposed design can be effectively and economically used in carbon dioxide mitigation technologies and in the production of algal biomass for biofuel and other bioproducts.

Keywords: algae photobioreactor, air-lift, internally lit, hydrodynamic design, specific growth rate

\section{INTRODUCTION}

Microalgae have several advantages over other biological sources as a feedstock for biofuels and bioproducts. Algae have a higher ratio of oil production to required cultivated area compared with common bioenergy sources such as corn, soybean, rapeseed, jatropha, and others (Chisti, 2008). Microalgae can also be used for starch production and its subsequent ethanol production through yeast fermentation, achieving efficiencies similar to the best available crops (Harun et al., 2010). Another characteristic of algae is that it can double its biomass at an exponential rate requiring less surface area for the production of biofuels and bioproducts (Framptona et al., 2013). Microalgae could also be used for carbon dioxide capture and recycling since $1.7 \mathrm{~kg}$ of $\mathrm{CO}_{2}$ is required for every kilogram of biomass generated (Ghorbani et al., 2014).

There are several advantages of photobioreactors over conventional open algal cultivation systems. Closed systems allow more precise control over critical algal growth parameters including $\mathrm{pH}$, nutrient delivery, light intensity, light cycle duration, ultraviolet exposure, and mixing (Kunjapur and Eldridge, 2010). Also, photobioreactors provide an isolated environment with a much lower probability of contamination by other algal strains or microorganisms. Typically, these reactors require less land for the same biomass production (Borowitzka, 1999). Finally, photobioreactors could extend the growth potential from a current few microorganism strains used in open systems to more than thousands of strains of phototropic algae (Tredici, 1999).

However, the design and scale up of photobioreactors still require further development. The most important areas have been identified as (1) efficient lighting processes, (2) efficient supply of carbon dioxide and oxygen removal, and (3) energy consumption for adequate mixing (Clemens, 2009). Light delivery remains a challenging problem for photobioreactor scale up. Surface lit photobioreactors require a large surface area to volume ratio to transmit enough light to support the photosynthetic process (Janssen et al., 2003). Extensive transparent surfaces are difficult and expensive to build, and the cells closer to the surface of the photobioreactor may be photo inhibited while cells in the center of the vessel may be photo limited affecting algal productivity (Gris et al., 2014). The literature present other internal lighting approaches such as plastic light guides (Zijffers et al., 2008) or internal fluorescent bulbs surrounded by glass containers (Ogbonna et al., 1996).

Fiber optics have also been proposed in the past to deliver light to microalgal cultures inside the reactor as an alternative to using glass tubes with outside radiation. Xue et al. (2013) proposed an air-lift photobioreactor using fiber optics but they encountered leakage problems in their design. Another bubble column bioreactor design incorporated optical fibers to control illumination where the fiber optics were introduced from the top of the column to avoid leakage issues (Bayless, 2007). This current work pursued the integration of an air-lift reactor design that incorporated fiber optic illumination. Here, we present the design process of the novel photobioreactor to address uniform light distribution, fiber optic support, and leakage prevention and results that indicate that this approach can be used for microalgae production. 


\section{MATERIALS AND METHODS \\ PHOTOBIOREACTOR DESIGN AND CONSTRUCTION}

The development of the novel air-lift photobioreactor followed the stages typical of a design process. The first part considered general aspects of the systems such as light and dark areas, size, and structural support. Subsequent considerations focused on fiber optic support and the hydrodynamic modeling of the system.

The conceptual design for the reactor is depicted in Figure 1. The height was $1171 \mathrm{~mm}$ with a volume of $28 \mathrm{~L}$. The air-lift reactor was composed of two zones; one illuminated and the other dark. This division combined with the induced circulation imposed light/dark cycles upon the microorganisms. Microalgae are continuously exposed to such cycles in nature as consequence of the mixing in the bodies of water (Peers et al., 2009), and the proposed photobioreactor provided an environment which simulated the natural conditions for microalgae. Although the specific design proposed by the researchers induces light cycles, the idea of using fiber optics inside the bioreactor could provide continuous exposure to light by extending the fiber array to both chambers of the bioreactor.

The containment vessel comprised materials that offer ease of construction and may be made leak proof at a reasonable cost compared to glass. A commercial material that was easy to obtain and work with was chosen for the construction, and material homogeneity was crucial to constructability and to maintain compatibility of the sub-components. It was also necessary to take into consideration important constraints of the material application such as permanent immersion under water, tolerance with microalgae, and stabilization properties.

Steel pipes were eliminated from consideration because of difficulty in fabrication (i.e., drilling and cutting) and the potential for corrosion in aqueous environments, and stainless steel was expensive. Acrylic was considered as it has been used in past photobioreactor applications (Hsieh and Wu, 2009); however, the acrylic bonding process is more complicated than other plastics and requires more expensive products. As the bonding process is well known and used in everyday pluming applications, PVC was chosen as the best commercial material for the laboratory unit. Both header and draft tube pipes were made of white PVC to maximize the reflection of the light inside the illuminated area. The reflection of the light waves by white plastic is beneficial for light availability in algal cultures (Slegers et al., 2013). This also provided a separation between the dark and light cycles. It should be noted that other materials will need to be evaluated in the future since it has been suggested that PVC could promote biofilm formation (Guzman et al., 2007).

The riser was illuminated with fiber optics that were directed through the header pipe placed in the center of the reactor as shown in Figures 1 and 2. The header served as the conduit to carry the fiber optic cables inside the reactor volume, as well as the gas supply line and provided ease of construction to avoid leakage problems. The optical fibers carried inside the header minimized interference with the algal growth and provided sufficient space for the 44 optical fibers (Figure 2). Once the fibers were directed from the light source into the header, a subsystem of plastic bolts was developed to uniformly distribute photons within the algal culture. The header and bolts also provided the structural support required
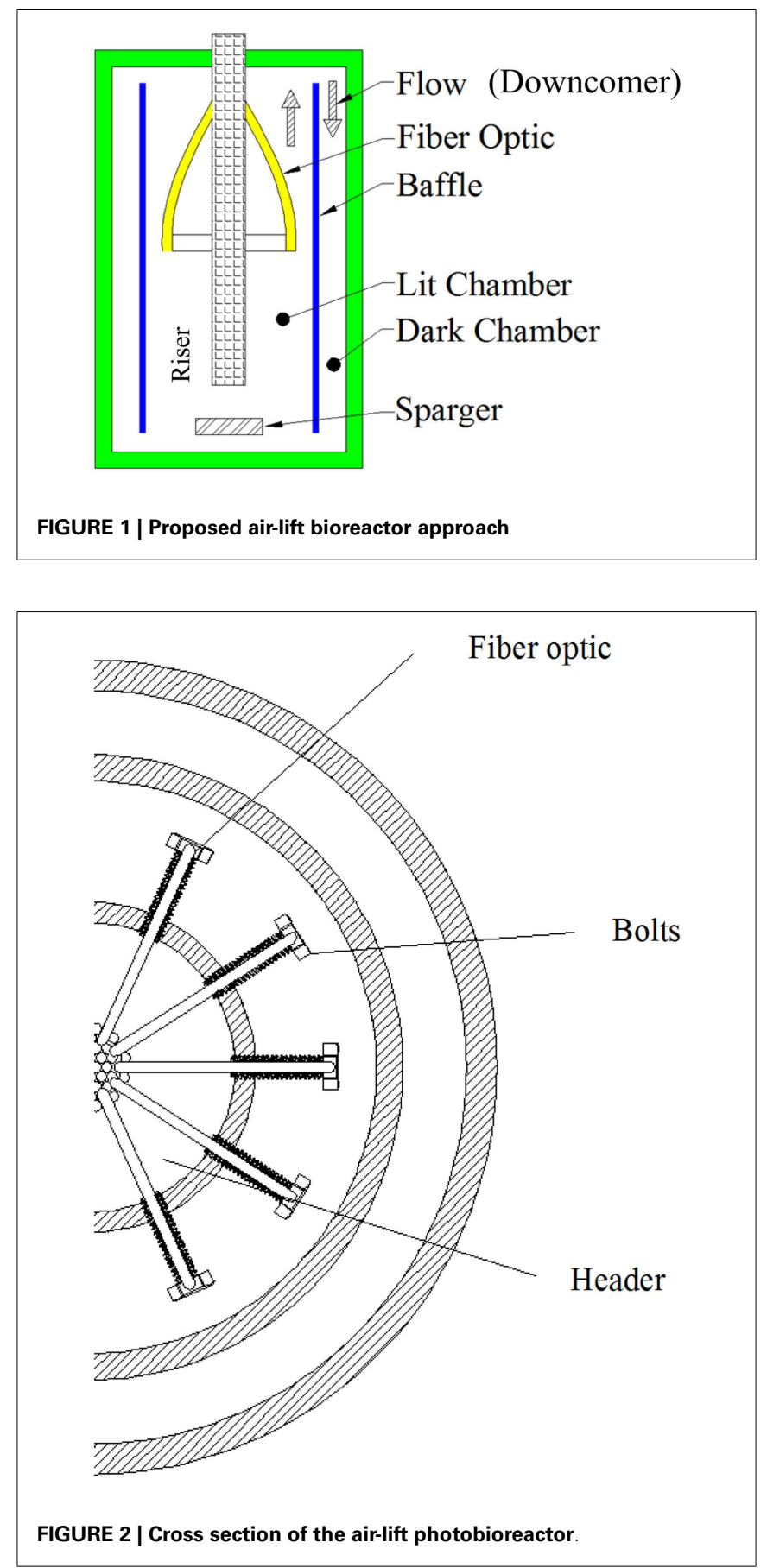

to hold the fiber optics in a specific location in the flow path of the growth media that carried the algal culture. A draft tube served as the required baffle to allow circulation of the growth media inside the air-lift device. The liquid flowed upwards in the area contained between the header and draft tube, while the media moved downward between the draft tube and the containment vessel (Figure 1, as indicated by arrows).

Adequate structural support for all system components was also addressed. The downcomer and riser were supported in a way to guarantee stability and prevent leaking of the algal culture. 
Since the air-lift reactor has an internal baffle, the design process also considered a support for the embedded system (not shown). The sparger was designed with four injection points as shown in Figure 6 to allow for adequate distribution of the gas inside the riser chamber while minimizing the possibility of biofouling. The position of the sparger was defined inside the baffle such that it optimizes the circulation flow as explained elsewhere (Chisti, 1989).

The size of the containment vessel was determined by a combination of two criteria; (1) the availability of the materials in the commercial market, and (2) air-lift systems should follow a general geometric rule. In order to guarantee smooth flow between the components, the ratio of downcomer area $\left(A_{d}\right)$ to riser area $\left(A_{r}\right)$ should be approximately unity (Chisti, 1989):

$$
\mathrm{A}_{\mathrm{r}} / \mathrm{A}_{\mathrm{d}} \cong 1
$$

The proposed design accommodated this geometric restriction through the selection of appropriate pipe diameters. Additionally, this ratio affects retention time in each section of the reactor and could easily be manipulated as a method of controlling light/dark cycle.

\section{LIGHT SYSTEM}

The proposed design used plastic optic fiber (POF) cables (PGRFB3000 ${ }^{\circledR}$, Moritex, USA) instead of glass primarily because POFs are stronger, supporting more stress and pressure than glass ones. Further, POFs have more flexibility and a smaller bending radius than glass systems, which is a primary reason they are broadly used in architectural and automobile applications. Finally, POFs are traditionally less expensive than optical fibers made of glass (Bailey, 2003).

This research used an artificial source to provide the light for growing the microalgae. The light source was a microscope illuminator powered with a EKE light bulb of $21 \mathrm{~V}$ and $150 \mathrm{~W}$ (GE lighting, Cleveland, OH, USA). Previous publications have suggested an optimum light intensity for microalgae between 80 and $120 \mu \mathrm{mol} /\left(\mathrm{s} \cdot \mathrm{m}^{2}\right.$ ) (Csavina, 2008; Li et al., 2012). In order to achieve the required light intensity inside the photobioreactor, it was necessary to determine the number of optical fibers at each level in the system to achieve the minimum target of $80 \mu \mathrm{mol} /\left(\mathrm{s} \cdot \mathrm{m}^{2}\right)$. This approach was based on the theoretical treatment of light as a particle (photon). First, the intensity provided by the light source was measured using a Li-cor LI 190 quantum sensor facing directly toward the light bulb. It was then possible to determine the number of micromoles of photons per fiber based on the area of each cable. Finally, the number of fibers required was computed taking into consideration the area of the riser previously defined and was determined to be eleven POFs per level (Table 1).

To confirm that the target light intensity $\left[80 \mu \mathrm{mol} /\left(\mathrm{s} \cdot \mathrm{m}^{2}\right)\right]$ was achieved with the eleven fibers per level, a column mockup was developed as shown in Figure 3. The rig was constructed using the same pipe dimensions as defined previously with two mounted optical fibers (Figure 3A). The results of the light readings are shown in Table 2. Figure 4 provides a front view of the
Table 1 | Light intensity calculations for the photobioreactor.

\begin{tabular}{lcc}
\hline Variable & Magnitude & Units \\
\hline Measured photon density of & $11,000 \pm 500$ & $\mu \mathrm{mol} /\left(\mathrm{s} \cdot \mathrm{m}^{2}\right)$ \\
the light source & 7 & \\
Area of the fiber & 0.08 & $\mathrm{~mm}{ }^{2}$ \\
Photons per fiber & 11 & $\mu \mathrm{mol} /(\mathrm{s} \cdot \mathrm{fiber})$ \\
Number of fibers per level & 0.91 & $\mathrm{fibers}$ \\
Total incident light per level & 73 & $\mu \mathrm{mol} / \mathrm{s}$ \\
Average irradiance per level & &
\end{tabular}

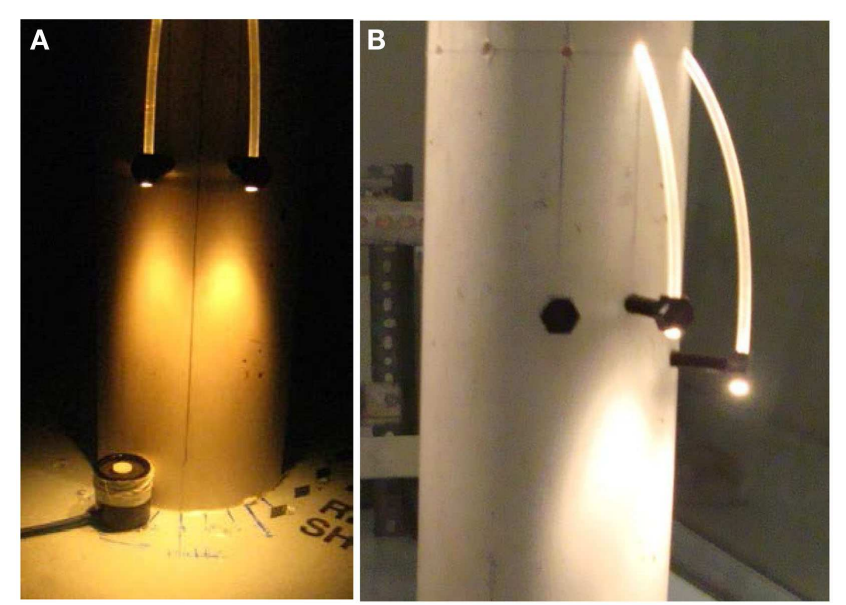

FIGURE 3 | (A) Measurement of light levels inside the photobioreactor; (B) Different level spacing's under consideration.

Table 2 | Light intensity levels inside the reactor.

Level distance $(\mathrm{mm})$ Light intensity $\mu \mathrm{mol} /\left(\mathrm{s} \cdot \mathrm{m}^{2}\right)$ for each position

\begin{tabular}{lrrrrrrrr}
\cline { 2 - 7 } & $\mathbf{1}$ & $\mathbf{2}$ & $\mathbf{3}$ & $\mathbf{4}$ & $\mathbf{5}$ & $\mathbf{6}$ & $\mathbf{7}$ & Peak \\
\hline 35 & 55 & 437 & 544 & 215 & 599 & 603 & 98 & 603 \\
95 & 124 & 170 & 206 & 213 & 211 & 185 & 144 & 213 \\
120 & 63 & 84 & 99 & 103 & 105 & 98 & 69 & 105
\end{tabular}

measurement taken between two POFs. Positions 1 and 7 measured the lowest light intensity since the light sensor was placed outside both POFs, respectively as indicated in Figure 4. Positions 2 and 3 were beneath the first POF light stream, positions 5 and 6 were beneath the second POF, while position 4 was in the middle of both POFs. The average and peak light intensities at all distances exceeded the required target; however, since actual light levels during growth conditions will be lower as the concentration of microalgae increases, it was concluded that the proposed spacing of $120 \mathrm{~mm}$ will meet the minimum light requirement even with high density cultures.

Bolts provided the necessary support required while maintaining a structurally sound point for the fiber optic cables (Figures 3 and 4). To maintain material compatibility with the pipes, PVC 


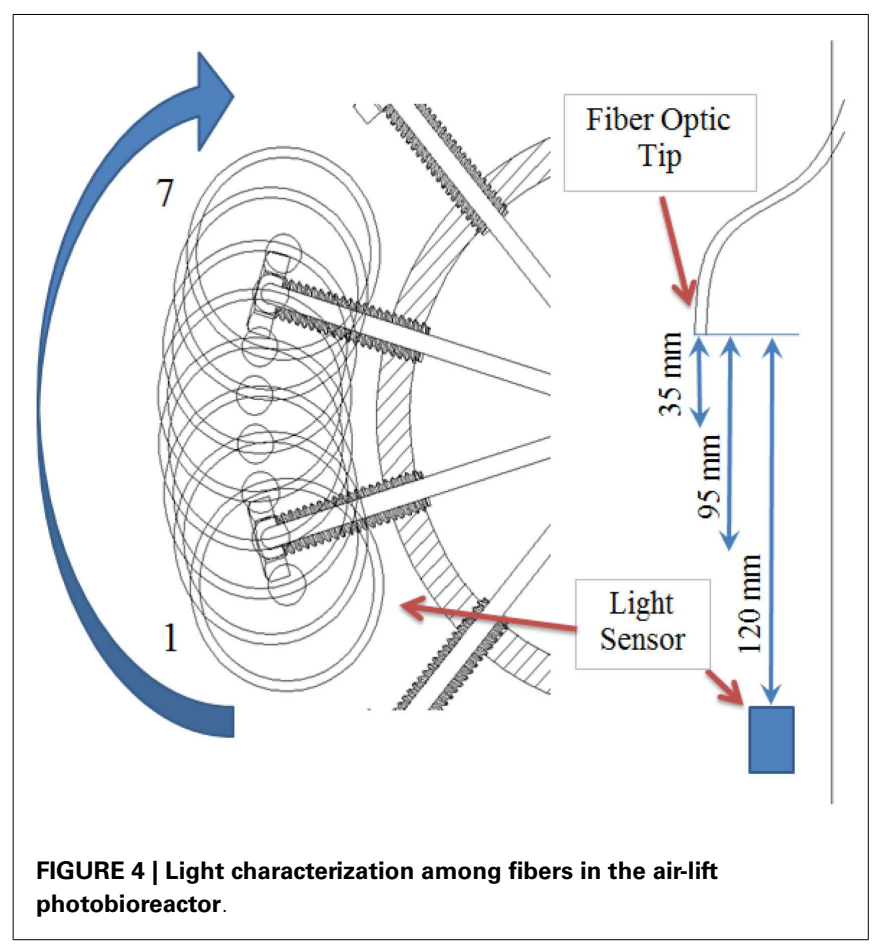

bolts were chosen as the element to provide the support. The proposed design consisted of eleven bolts per level, where each bolt had a hole in the head equal to the diameter of the POF. The bolts were attached to the header via a threaded hole, providing enough strength for a robust construction. This was important to assure that the bending force of the fiber optic did not loosen or release the bolts from their place. Additionally, the threaded joints permitted quick disassembly of the bolts to allow for future modifications to the number of fibers or levels.

\section{FINAL DIMENSIONS AND CIRCULATION MODEL}

The optimum mixing velocity in algal cultures is a tradeoff between efficient mass transfer and minimizing shear stresses. An extensive literature review was performed to determine liquid and gas velocities used in past algal bioreactors (Table 3). Previous studies have been successful growing algae in the superficial gas velocity $\left(U_{g}\right)$ range of $0.07-2.5 \mathrm{~cm} \mathrm{~s}^{-1}$, while an upper limit of $3.4 \mathrm{~cm} \mathrm{~s}^{-1}$ was reported as the onset of cell damage due to shear stress. Therefore, the average of the lowest and highest reported values was used as the superficial gas velocity for the demonstration tests.

The modeling equations proposed by Chisti were solved by iteration of Eq. 2:

$$
U_{\mathrm{Lr}}=\left[\frac{2 g h_{D}\left(\varepsilon_{r}-\varepsilon_{d}\right)}{K_{B}\left(\frac{A_{r}}{A_{d}}\right)^{2} \frac{1}{\left(1-\varepsilon_{d}\right)^{2}}}\right]^{0.5}
$$

where $\boldsymbol{U}_{\mathrm{Lr}}$ is the superficial liquid velocity, $\boldsymbol{g}$ is gravity, $\boldsymbol{h}_{d}$ is the height of the column, $\boldsymbol{\varepsilon}_{r}$ and $\boldsymbol{\varepsilon}_{d}$ are the gas holdup in the riser and downcomer, and $\boldsymbol{K}_{b}$ is the frictional loss coefficient. The gas hold up is the volumetric ratio of gas in the liquid (volume of gas per
Table 3 | Calculated superficial gas velocities for previous air-lift and bubble column reactors reported in the literature.

\begin{tabular}{|c|c|c|c|c|}
\hline Study & $\begin{array}{l}\text { Reactor } \\
\text { diameter } \\
\text { (cm) }\end{array}$ & Type & $\begin{array}{l}\mathrm{Ug} \\
\left(\mathrm{cm} \mathrm{s}^{-1}\right)\end{array}$ & $\begin{array}{l}\text { Gas } \\
\text { Flow } \\
\left(\mathrm{L} \mathrm{min}^{-1}\right)\end{array}$ \\
\hline Ranjbar et al. (2008) & 4.6 & Air Lift & 0.07 & 0.1 \\
\hline Ranjbar et al. (2008) & 4.6 & Air Lift & 0.13 & 0.1 \\
\hline $\begin{array}{l}\text { Vasconcelos Barbosa } \\
\text { (2003) }\end{array}$ & 3.5 & Bubble Column & 0.50 & 0.3 \\
\hline $\begin{array}{l}\text { Vasconcelos Barbosa } \\
\text { (2003) }\end{array}$ & 21 & Bubble Column & 0.60 & 12.5 \\
\hline $\begin{array}{l}\text { García Camacho } \\
\text { et al. (1999) }\end{array}$ & 8 & Bubble Column & 1.00 & 3.0 \\
\hline This research & 20.3 & Air Lift & 1.80 & 13.3 \\
\hline $\begin{array}{l}\text { Vasconcelos Barbosa } \\
\text { (2003) }\end{array}$ & 21 & Bubble Column & 2.50 & 52.0 \\
\hline $\begin{array}{l}\text { Vasconcelos Barbosa } \\
\text { (2003) }\end{array}$ & 3.5 & Bubble Column & 3.40 & 2.0 \\
\hline $\begin{array}{l}\text { García Camacho } \\
\text { et al. (1999) }\end{array}$ & 8 & Bubble Column & 5.00 & 15.1 \\
\hline
\end{tabular}

volume of liquid), and the superficial liquid velocity is the velocity of the liquid without the gas fraction. The true liquid velocity considers the gas fraction in the volume and therefore is higher than the superficial liquid velocity. Velocities for different gas flow rates are shown in Table 4 with the selected gas flow rate for our design shown in gray.

The expected superficial liquid velocity in the riser was $9.2 \mathrm{~cm} \mathrm{~s}^{-1}$ and the true liquid velocity was $9.6 \mathrm{~cm} \mathrm{~s}^{-1}$. Based on the length of the riser $(70 \mathrm{~cm})$, the model predicted a mean cell residence time (MCRT) of $8 \mathrm{~s}$ in the riser section. This period is also the light side period of the circulation. The model also predicted a true liquid velocity in the downcomer of $14 \mathrm{~cm} \mathrm{~s}^{-1}$, yielding a MCRT in the dark side of the system of $5 \mathrm{~s}$. As the total system MCRT was expected to be $18 \mathrm{~s}$, an algal cell would be in the riser for $8 \mathrm{~s}$, in the downcomer for $5 \mathrm{~s}$, and held up in the bottom and upper connection chambers of the system for an additional $5 \mathrm{~s}$.

\section{CIRCULATION TESTS}

A non-reactive tracer test was performed to determine the velocities and mixing characteristics of the proposed photobioreactor. A peristaltic pump was used to sample at a constant volumetric flow rate from two points of the reactor (top and bottom) through separate sample lines. The reactor was filled with $\mathrm{RO}$ water and $10 \mathrm{~mL}$ of a $1 \mathrm{mM} \mathrm{NaCl}$ solution was injected through the top flange at the beginning of the test. Three aliquots were sampled every $5 \mathrm{~s}$ to measure the change in the Chloride ion concentration. The vials were analyzed via Ion Chromatograph (Dionex, 25A) equipped with an AS14A Column.

\section{PRODUCTIVITY TESTS}

Five tests were performed to determine the specific growth rate in the photobioreactor and develop the operation and maintenance procedures of the bioreactor. The alga that was used for all the tests was Chlorella sp. (UTEX, 2714) and two experiments used the 
Table 4 | Calculated MCRTs for different gas flow rates.

\begin{tabular}{|c|c|c|c|c|c|c|}
\hline $\begin{array}{l}\text { Gas hold } \\
\text { up (\%) }\end{array}$ & $\begin{array}{l}\text { Gas flow } \\
\text { rate }\left(\mathrm{L} \mathrm{min}^{-1}\right)\end{array}$ & $\begin{array}{l}\text { Total } \\
\text { MCRT (s) }\end{array}$ & $\begin{array}{l}\text { MCRT } \\
\text { riser (s) }\end{array}$ & $\begin{array}{l}\text { Superficial gas } \\
\text { velocity }\left(\mathrm{cm} \mathrm{s}^{-1}\right)\end{array}$ & $\begin{array}{l}\text { Superficial liquid } \\
\text { velocity }\left(\mathrm{cm} \mathrm{s}^{-1}\right)\end{array}$ & $\begin{array}{l}\text { True liquid } \\
\text { velocity }\left(\mathrm{cm} \mathrm{s}^{-1}\right)\end{array}$ \\
\hline 3.0 & 9 & 20 & 11 & 0.9 & 7.8 & 8.1 \\
\hline 3.7 & 11 & 19 & 10 & 1.2 & 8.5 & 8.9 \\
\hline 4.2 & 13.3 & 18 & 10 & 1.8 & 9.2 & 9.6 \\
\hline 4.8 & 16 & 17 & 9 & 2.2 & 9.7 & 10.2 \\
\hline 5.3 & 18 & 16 & 9 & 2.5 & 10.2 & 10.8 \\
\hline
\end{tabular}

commercial nutrient product Botanicare ${ }^{\circledR}$ and three experiments used Bristol media (as recommended by UTEX). The motivation for investigating the commercial product Botanicare ${ }^{\circledR}$ was to replace the expense of a defined media (Bristol) with a more economical nutrient source. Botanicare ${ }^{\circledR}$ is composed of $3 \%$ soluble nitrogen, $2 \% \mathrm{P}_{2} \mathrm{O}_{5}, 4 \% \mathrm{~K}_{2} \mathrm{O}, 1 \% \mathrm{Ca}$, and $0.5 \% \mathrm{Mg}$. However, as explained below, it was necessary to transition to Bristol media due to $\mathrm{pH}$ control issues when using Botanicare ${ }^{\circledR}$ (UTEX Bristol Media Recipe).

All productivity tests were performed under the same air flow rate of 13.3 LPM. As the bubble flow in the constrained space (riser) provided a continuous agitation over the optical fiber tips, it was assumed this action would keep them clean from algal attachment and fouling. The disassembling and inspection of the internal components of the reactor between each run verified the cleaning action of the bubbles when using Botanicare ${ }^{\circledR}$ as the media as shown in Figure 6. However, the tests performed with Bristol media demonstrated significant algal attachment to the internal walls of the bioreactor. Nevertheless, the tips of POF were never covered by microalgae ensuring the light delivery through the growth cycle.

\section{GROWTH RATE MEASUREMENT}

Samples were obtained through a draining valve which was flushed prior to sample collection to assure that the sampled liquid was representative of the current culture. A $40 \mathrm{~mL}$ aliquot of the algal culture was drained daily from the reactor and three $8 \mathrm{~mL}$ volumes were separated from the sample and their in vivo fluorescence determined and recorded. The standard deviation shown in Figures 7 and $\mathbf{8}$ correspond to $n=3$ for each reading. The fluorometer used to determine the chlorophyll $a$ readings was a TD 700 (Turner Designs, CA, USA). The fluorometer calibration was checked biweekly by the use of a Red Solid Standard. The remaining sample volume was used to determine the $\mathrm{pH}$ using a pHtestr $3+$ (Oakton, Vernon Hills, IL, USA). The target $\mathrm{pH}$ was $6.8 \pm 1.0$ based on the UTEX media specifications. However, maintaining this target was particularly difficult when using Botanicare ${ }^{\circledR}$ since this product has a $\mathrm{pH}$ close to 2 in a concentrated solution without buffer. This created $\mathrm{pH}$ swings that affected the growth of the microalgae in the bioreactor for Test \#1.

To develop the correlation between cell count and fluorescence, samples were diluted until a chlorophyll $a$ concentration lower than $10 \mu \mathrm{g} \mathrm{L}^{-1}$ was achieved. The dilution was recorded and the number of cells in the diluted sample was determined using a microscope and a Nannoplankton chamber (ID\#533, Phycotech, MI, USA). The variation in the number of cells was compared to

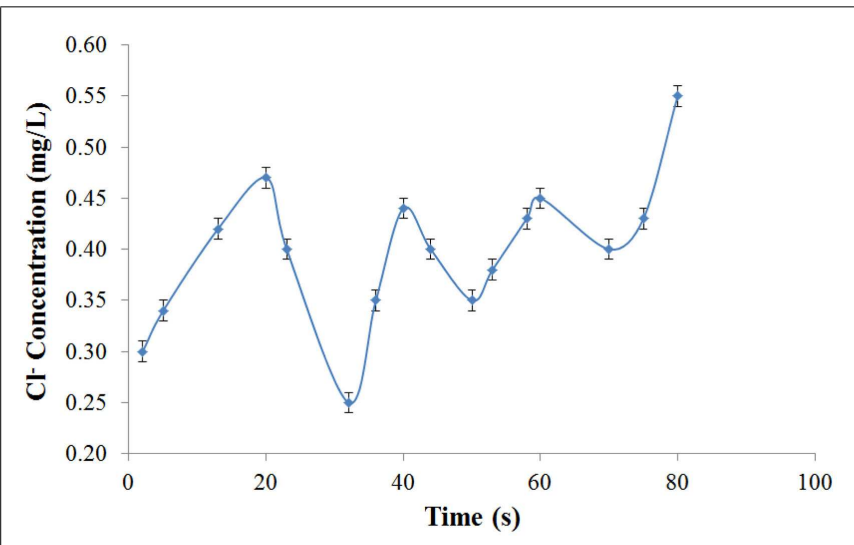

FIGURE 5 | Circulation test in the bioreactor

the in vivo fluorescence of the algal strain and a linear correlation was obtained with an $R^{2}$ of 0.965 .

The specific growth rate constant $(\mu)$ for different intervals was calculated for each test based on Eq. 3 where $N_{i}$ and $N_{f}$ are the cell populations at the initial and final time. This equation was used to calculate $\mu$ for specific time intervals as described below (Wood et al., 2005).

$$
\mu=\frac{\ln \left(N_{i} / N_{f}\right)}{t_{f}-t_{i}}
$$

\section{RESULTS AND DISCUSSION CIRCULATION TIME}

A mixing characterization experiment was developed to validate the theoretical model. The change in chloride concentration with time is provided in Figure 5. The oscillation in the concentration is caused by the upward and downward circulation in the air-lift system as predicted by the equations and can be analyzed to determine experimental MCRT. These results show that the MCRT of the system is between 21 and $22 \mathrm{~s}$; slightly longer than the predicted time of $18 \mathrm{~s}$. The increased experimental MCRT is most likely attributable to slightly larger than predicted holdup volumes at the top and bottom of the reactor.

\section{PRODUCTIVITY}

The increase in cell density and the corresponding $\mathrm{pH}$ values over time for Tests 1 and 2 using Botanicare ${ }^{\circledR}$ as the growth media is presented in Figure 7. In Test 1, the biomass increased for $91 \mathrm{~h}$, 


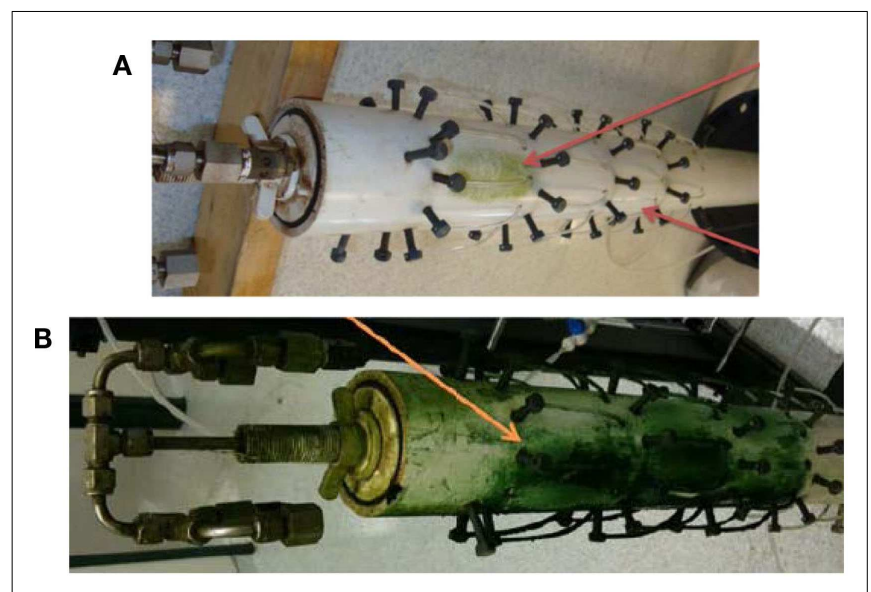

FIGURE 6 | (A) Cleaning action of the bubbles when using Botanicare $₫$ as the growth media. (B) Presence of bio fouling when using Bristol media.
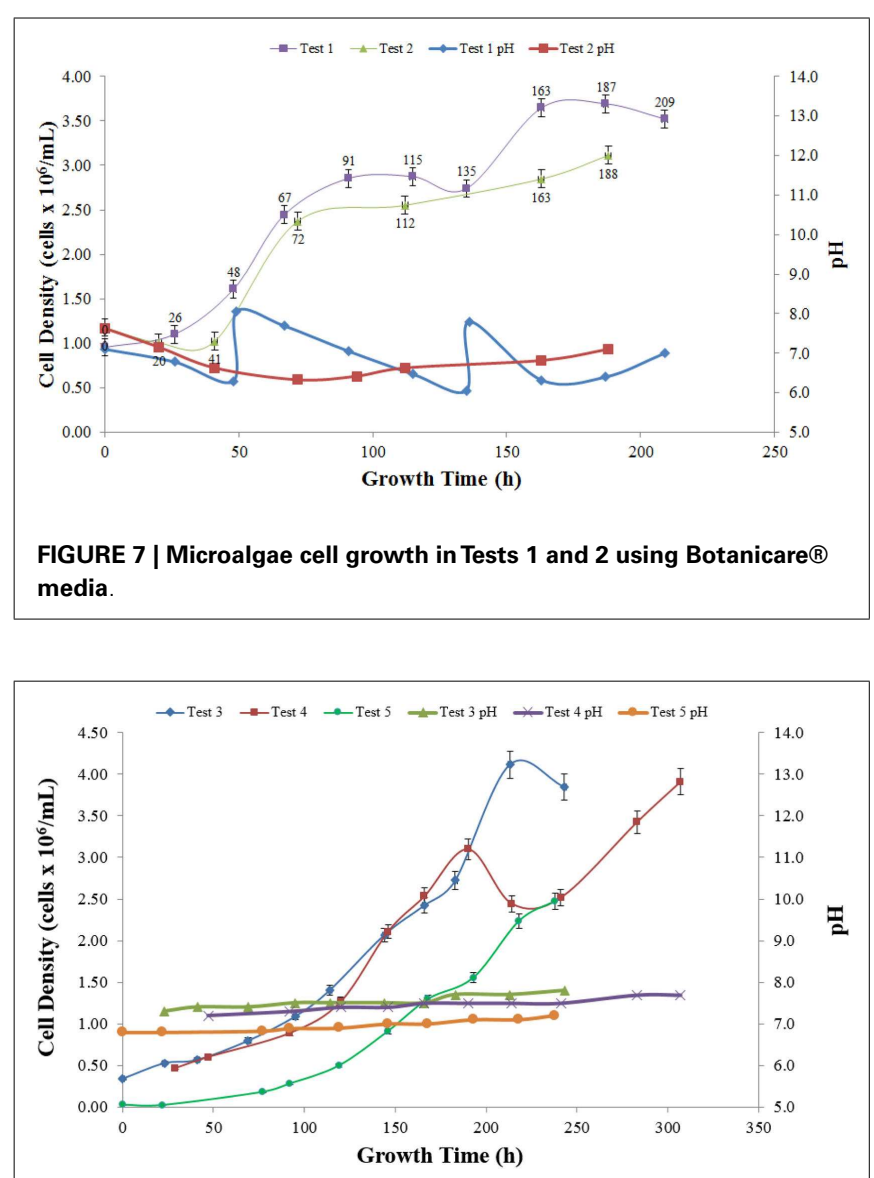

FIGURE 8 | Three productivity tests in the bioreactor using Bristol media.

then decreased slightly until hour 135. It is hypothesized that the drop in $\mathrm{pH}$ inhibited optimal growth conditions since the Botanicare media did not have any $\mathrm{pH}$ buffer. The increases in $\mathrm{pH}$ during Test 1 seen in Figure 7 correspond to an addition of $\mathrm{NaOH}$ needed
Table 5 | Selected productivity rates.

\begin{tabular}{lccc}
\hline Test & Interval (h) & $\begin{array}{l}\text { Growth } \\
\text { rate }\left(\mathbf{h}^{-\mathbf{1}}\right)\end{array}$ & $\begin{array}{l}\text { Linear coefficient of } \\
\text { determination }\end{array}$ \\
\hline 1 & $0-91$ & 0.013 & 0.95 \\
2 & $41-112$ & 0.012 & 0.78 \\
3 & $0-213$ & 0.011 & 0.99 \\
4 & $0-190$ & 0.012 & 0.98 \\
5 & $0-238$ & 0.021 & 0.94 \\
\hline
\end{tabular}

to raise the $\mathrm{pH}$ to a more suitable biological range. The exponential growth constant for Test 1 between 0 and $91 \mathrm{~h}$ was $0.013 \mathrm{~h}^{-1}$ $\left(R^{2}=0.955\right)$, with maximum growth between hours 48 and 67 $\left(\mu=0.022 \mathrm{~h}^{-1}\right)$. Test 2 exhibited a slight decrease in Chlorophyll a concentration during the first $41 \mathrm{~h}$, indicating that a period of acclimatization was experienced by the algae. This was followed by a consistent increase over the remaining $160 \mathrm{~h}$, resulting in an average growth rate between hours 41 and 112 of $0.012 \mathrm{~h}^{-1}$ $\left(R^{2}=0.78\right)$ and a maximum specific growth rate over interval $41-72 \mathrm{~h}$ of $0.027 \mathrm{~h}^{-1}$.

Figure 8 presents the growth curves for Tests 3-5 and growth rate data for selected intervals representative of the average of the five tests are presented in Table 5. The Chlorella culture in Test 3 exhibited sustained growth from 0.4 to $4.0 \times 10^{6}$ cells $\mathrm{mL}$ over $213 \mathrm{~h}$, resulting in a calculated productivity of $0.011 \mathrm{~h}^{-1}$ with an $R^{2}$ coefficient of 0.99 . The biomass decrease at the end was assumed to be due to achievement of stationary phase of the culture. Test 4 demonstrated an increase in biomass over time, resulting in an average specific growth rate over the first $161 \mathrm{~h}$ of $0.012 \mathrm{~h}^{-1}$ and a maximum rate between hours 120 and 146 of $0.020 \mathrm{~h}^{-1}$. The decrease in fluorescence at hour 214 corresponds with an interruption in the light source (burned-out bulb), but recovery upon replacement was immediate and aggressive. Test 5 exhibited a specific growth rate of $0.022 \mathrm{~h}^{-1}$ with an $R^{2}$ of 0.94 . This rate is similar to the maximum growth rate seen in each of the previous tests and is the same as the value of $0.022 \mathrm{~h}^{-1}$ reported in the literature for optimized systems (Miron Sanchez et al., 2000).

Table 5 summarizes the growth rate data for all five tests. Overall, the novel internally lit photobioreactor achieved growth rates previously reported in the literature for optimized systems indicating that fiber optics could be used as tool for light delivery to microalgal cultures. Further work is required to optimize system operation (e.g., pH control), explore larger volumes, and develop a comparison between internally lit and outdoor designs.

\section{CONCLUSION}

The novel internally lit air-lift algae bioreactor was able to operate successfully for 3 months without leakage of the media or major modifications. All internal components of the system and subsystems remained operative and a simple maintenance procedure was developed for cleaning and continued operation. The minimum average light intensity in the illuminated chamber was $89 \mu \mathrm{mol} /\left(\mathrm{s} \cdot \mathrm{m}^{2}\right)$ with the proposed arrangement of 11 fiber optic cables per level; in excess of the defined lower target of $80 \mu \mathrm{mol} /\left(\mathrm{s} \cdot \mathrm{m}^{2}\right)$ and validating the calculation that determined 
the number of fibers required from the reactor section mock-up. Although some biofilm was detected on the walls of the reactor for three of the tests, the air bubbles demonstrated an effective cleaning effect over the fiber optics as evidenced by the fact that the fiber optic cables tips were never found to be clogged during the visual inspections after three months of operation.

Chlorella vulgaris was successfully grown at different specific constant growth rates in the air-lift system. A mean specific growth rate constant of $0.011 \mathrm{~h}^{-1}$ was achieved for periods over $140 \mathrm{~h}$ with maximum rates exceeding $0.020 \mathrm{~h}^{-1}$ for each of the five tests. Further, Test 5 demonstrated a sustained a growth rate of $0.020 \mathrm{~h}^{-1}$ over the $240 \mathrm{~h}$ duration of the experiment. These results collectively demonstrate that an internally lit photobioreactor can be used for microalgal cultures as an option to current glass photobioreactors. More work is required to scale up the system and perform a comparison with outdoor designs.

\section{ACKNOWLEDGMENTS}

This work was funded in part by a grant from the US Department of Energy (award number DE-FG36-08GO88083).

\section{REFERENCES}

Bailey, D. (2003). Practical Fiber Optics. Perth: Elsevier, 81-93.

Bayless, D. (2007). Apparatus and Method for Growing Biological Organisms for Fuel and Other Purposes. United States of America Patent 0264708.

Borowitzka, A. (1999). Commercial production of microalgae: ponds, tanks, tubes and fermenters. J. Biotechnol. 70, 313-321. doi:10.1016/S0168-1656(99) 00083-8

Chisti, Y. (1989). Air Lift Bioreactors. New York, NY: Elsevier Applied Science, 12-29.

Chisti, Y. (2008). Biodiesel from microalgae beats bioethanol. Trends Biotechnol. 26, 126-131. doi:10.1016/j.tibtech.2007.12.002

Clemens, P. (2009). Design principles of photo-bioreactors for cultivation of microalgae. Eng. Life Sci. 9, 165-177. doi:10.1007/s00449-013-0898-2

Csavina, J. (2008). The Optimization of Growth Rate and Lipid Content from Select Algae Strains. MS thesis, Ohio University, Athens.

Framptona, M. F., Gurneya, R. H., Dunstana, G. A., Clementsona, L. A., Toiflc, M. C., Pollardc, C. B., et al. (2013). Evaluation of growth, nutrient utilization and production of bioproducts by a wastewater-isolated microalga. Bioresour. Technol. 130, 261-268. doi:10.1016/j.biortech.2012.12.001

García Camacho, F., Contreras Gómez, A., Acién Fernández, F. G., Fernández Sevilla, J., and Grima, E. M. (1999). Use of concentric-tube airlift photobioreactors for microalgal outdoor mass cultures. Enzyme Microb. Technol. 24, 164-172. doi:10.1016/S0141-0229(98)00103-3

Ghorbani, A., Rahimpour, H. R., Ghasemi, Y., Zoughi, S., and Rahimpour, M. R. (2014). A review of carbon capture and sequestration in Iran: microalgal biofixation potential in Iran. Renew. Sust. Energy Rev. 35, 73-100. doi:10.1016/j.rser. 2014.03.013

Gris, B., Morosinotto, T., Giacometti, G. M., Bertucco, A., and Sforza, E. (2014). Cultivation of Scenedesmus obliquus in photobioreactors: effects of light intensities and light-dark cycles on growth, productivity, and biochemical composition. Appl. Biochem. Biotechnol. 172, 2377-2389. doi:10.1007/s12010013-0679-z

Guzman, K., La Motta, E. J., McCorquodale, J. A., Rojas, S., and Ermogenous, M. (2007). Effect of biofilm formation on roughness coefficient and solids deposition in small-diameter PVC sewer pipes. J. Environ. Eng. 133, 364-371. doi:10.1061/(ASCE)0733-9372(2007)133:4(364)

Harun, R., Danquaha, M. K., and Fordea, G. M. (2010). Microalgal biomass as a fermentation feedstock for bioethanol production. J. Chem. Technol. Biotechnol. 85, 199-203. doi:10.1002/jctb.2287
Hsieh, C. H., and Wu, W. T. (2009). A novel photobioreactor with transparent rectangular chambers for cultivation of microalgae. Biochem. Eng. J. 46, 300-305. doi:10.1016/j.bej.2009.06.004

Janssen, M., Tramper, J., Mur, L. R., and Wijffels, R. H. (2003). Enclosed outdoor photobioreactors: light regime, photosynthetic efficiency, scale-up, and future prospects. Biotechnol. Bioeng. 81, 193-210. doi:10.1002/bit.10468

Kunjapur, A. M., and Eldridge, R. B. (2010). Photobioreactor design for commercial biofuel production from microalgae. Ind. Eng. Chem. Res. 49, 3516-3526. doi:10.1021/ie901459u

Li, Y., Zhou, W., Hu, B., Min, M., Chen, P., and Ruan, R. (2012). Effect of light intensity on algal biomass accumulation and biodiesel production for mixotrophic strains Chlorella kessleri and Chlorella protothecoide cultivated in highly concentrated municipal wastewater. Biotechnol. Bioeng. 109, 2222-2229. doi:10.1002/bit.24491

Miron Sanchez, A., Garcia Camacho, F., Contreras Gomez, A., and Molina Grima, E. (2000). Bubble column and airlift photobioreactors for algal culture. AIChE J. 46, 1872-1887. doi:10.1002/aic.690460915

Ogbonna, J. C., Yada, H., Masui, H., and Tanaka, H. (1996). A novel internally illuminated stirred tank photobioreactor for large-scale cultivation of photosynthetic cells. J. Ferment. Bioeng. 82, 61-67. doi:10.1016/0922-338X(96)89456-6

Peers, G., Truong, T., Ostendorf, E., Busch, A., Elrad, D., Grossman, A., et al. (2009). An ancient light-harvesting protein is critical for the regulation of algal photosynthesis. Nature 462, 518-521. doi:10.1038/nature08587

Ranjbar, R., Inoue, R., Katsuda, T., Yamaji, H., and Katoh, S. (2008). High efficiency production of astaxanthin in an air lift photobioreactor. J. Biosci. Bioeng. 106-2, 204-207. doi:10.1263/jbb.106.204

Slegers, P. M., van Beveren, P. J., Wijffels, R. H., van Straten, G., and van Boxtel, A. J. (2013). Scenario analysis of large scale algae production in tubular photobioreactors. Appl. Energy 105, 395-406. doi:10.1016/j.apenergy.2012.12.068

Tredici, M. (1999). The Encyclopedia of Bioprocess Technology. New York, NY: John Wiley.

UTEX. Available at: http://www.sbs.utexas.edu/utex/algaeDetail.aspx?algaeID= 5235

UTEX Bristol Media Recipe. Available at: http://www.sbs.utexas.edu/utex/ mediaDetail.aspx?mediaID $=29$

Vasconcelos Barbosa, M. (2003). Microalgal Photobioreactors: Scale Up and Optimization, Ph. D. thesis. Wageningen: Wageningen University.

Wood, A. M., Everroad, R. C., and Wingard, L. M. (2005). Measuring Growth Rates in Microalgal Cultures. Algal Culturing Techniques. San Diego, CA: Elsevier Academic Press, 269-285.

Xue, S., Zhang, Q., Wu, X., Yan, C., and Wei, C. (2013). A novel photobioreactor structure using optical fibers as inner light source to fulfill flashing light effects of microalgae. Bioresour. Technol. 138, 141-147. doi:10.1016/j.biortech.2013.03.156

Zijffers, J. W. F., Janssen, M., Tramper, J., and Wijffels, R. H. (2008). Design process of an area-efficient photobioreactor. Mar. Biotechnol. 10, 404-415. doi:10.1007/s10126-007-9077-2

Conflict of Interest Statement: The authors declare that the research was conducted in the absence of any commercial or financial relationships that could be construed as a potential conflict of interest.

Received: 31 August 2014; accepted: 20 December 2014; published online: 23 January 2015.

Citation: Hincapie E and Stuart BJ (2015) Design, construction, and validation of an internally lit air-lift photobioreactor for growing algae. Front. Energy Res. 2:65. doi: 10.3389/fenrg.2014.00065

This article was submitted to Bioenergy and Biofuels, a section of the journal Frontiers in Energy Research.

Copyright $\odot 2015$ Hincapie and Stuart. This is an open-access article distributed under the terms of the Creative Commons Attribution License (CC BY). The use, distribution or reproduction in other forums is permitted, provided the original author $(s)$ or licensor are credited and that the original publication in this journal is cited, in accordance with accepted academic practice. No use, distribution or reproduction is permitted which does not comply with these terms. 